\title{
Succession in intertidal mussel bed assemblages on different shores: species mobility matters
}

\author{
Nelson Valdivia ${ }^{1, *}$, Christian Buschbaum ${ }^{2}$, Martin Thiel ${ }^{3,4}$ \\ ${ }^{1}$ Universidad Austral de Chile, Instituto de Ciencias Marinas y Limnológicas, Laboratorio Costero de Recursos Acuáticos \\ Calfuco, Campus Isla Teja, Valdivia, Chile \\ ${ }^{2}$ Alfred Wegener Institute, Helmholtz Centre for Polar and Marine Research, Wadden Sea Station Sylt, Hafenstrasse 43 , \\ 25992 List/Sylt, Germany \\ ${ }^{3}$ Facultad de Ciencias de Mar, Universidad Católica del Norte, Larrondo 1281, Coquimbo, Chile \\ ${ }^{4}$ Centro de Estudios Avanzados en Zonas Aridas (CEAZA), Coquimbo, Chile
}

\begin{abstract}
Biogenic substrata such as epibenthic mussel aggregations are common in coastal regions worldwide and harbour diverse assemblages of sessile and mobile species. However, colonisation patterns on biogenic substrata are still not well understood. We tested whether succession develops as a linear sequence of temporal changes in the species richness and community structure of sessile and mobile assemblages associated with intertidal mussel beds of sedimentary and rocky shores in Germany and Chile, respectively. Because of their broad differences, these study sites were analysed separately to examine whether similar successional patterns occur under differing environmental conditions and species pools. At each study site, we conducted an experiment that separates the effects of successional age (deployment duration) and the time when settlement substrata are deployed (deployment timing). Colonisation dynamics differed between timings and between sessile and mobile species. In addition, timing effects were stronger at the sedimentary than at the rocky study site. For sessile organisms, for example, species richness increased steadily with successional age at both study sites, but at the sedimentary site, the magnitude of this increase varied between the different months of deployment. For mobile organisms, a high proportion of the total species pool colonised the settlement substrata within the first month of deployment at both sites. After this initial colonization peak, mobile species richness showed a minor but significant increase with successional age at both sites. We suggest that species dispersal ability at the local scale (mobility) mediates the response of species-rich assemblages to natural and anthropogenic disturbances.
\end{abstract}

KEY WORDS: Context-dependency $\cdot$ Determinism - Facilitation · Hard-bottom · Soft-bottom • Stochastic $\cdot$ Succession

\section{INTRODUCTION}

Understanding how communities assemble after a major disturbance (i.e. succession) is becoming increasingly important for both basic and applied ecology (Prach \& Walker 2011). This can be particularly relevant for patchy habitats like algal turfs, kelp holdfasts, seagrasses, and mussel beds, which are common in coastal regions worldwide and are colonised by species-rich assemblages of sessile and mobile organisms (Jones et al. 1994, Bishop et al. 2012). Biogenic habitats such as mussel and seagrass beds have been recognised as biodiversity hotspots, some of which have experienced significant losses over the last decades (Lotze et al. 2006, Smith et al. 2006). However, the colonisation process within com- 
plex biogenic habitats is unclear, and successional patterns still need to be properly documented (Underwood \& Chapman 2006).

Most successional models distinguish between early-colonising species, with characteristics like abundant offspring and high growth rates, and latecolonising species, with characteristics like strong competitive abilities and slow grow rates (e.g. Connell \& Slatyer 1977, Farrell 1989). These models were originally based on the dynamics of sessile species (Connell \& Slatyer 1977). However, organisms with different degrees of mobility can show contrasting patterns of colonisation (Antoniadou et al. 2011). For sessile species, access to suitable settlement substratum is an essential factor, because once settled they can no longer change their position and, therefore, cannot avoid competition and predation (Buss 1979). Therefore, the risk of competitive exclusion can be high among sessile settlers (e.g. Connolly \& Muko 2003), and the composition of early sessile colonisers can determine the successional pathways of the assemblage (Benedetti-Cecchi 2000a). On the other hand, mobile organisms actively move among habitat patches (e.g. Thiel et al. 2003), resulting in rapid colonisation of recently cleared substratum (Norderhaug et al. 2002). For example, peracarid assemblages colonising recently cleared habitats show a high daily turnover rate (>30\%, Edgar 1992), reaching a stable density within days (Taylor 1998). Depending on the disturbance size, communities of mobile colonisers should assemble rapidly, because all potential members should be present in surrounding areas from which they can immigrate (Norkko et al. 2006, Koivisto \& Westerbom 2012). Thus, mobility as a life-history trait that influences colonising abilities should be considered in the analysis of successional patterns.

Temporal variability in environmental conditions at the moment when a community is disturbed will result in a particular assemblage of early colonisers (e.g. Berlow 1997, Benedetti-Cecchi 2000a, Cifuentes et al. 2007). Successional studies should therefore be designed to start at different times, to span different periods of colonisation, and to end at different times (Underwood \& Chapman 2006). Manipulative field experiments are ideal to determine these successional patterns. However, the generalisation of conclusions drawn from manipulative experiments is compromised when they are limited in temporal and spatial extent (Menge 1991). One approach to overcome this problem is to test whether local patterns are consistent across identical small-scale experiments replicated under different environmental conditions and species pools (Benedetti-Cecchi 2000b).
Beds of mytilid mussels occur worldwide and in both sedimentary and rocky ecosystems (Thiel \& Ullrich 2002), providing an opportunity to investigate the colonisation processes in patchy habitats. Mussels can ameliorate physical stress (e.g. desiccation, wave battering, and temperature in intertidal areas) and are usually colonised within a few months by diverse assemblages of sessile and mobile species (Lohse 1993, Silliman et al. 2011). Enhanced availability of attachment substrata within biogenic substrata alleviates the strength of competition, leading to the idea that competitive hierarchies within these habitats are weak or even absent (Bruno et al. 2003, but see Wieters et al. 2009).

In replicate experiments conducted on sedimentary and rocky shores, we investigated the colonisation process of mussel-associated assemblages. The experiments were conducted at 2 study sites: the Wadden Sea in northwestern Europe, where the blue mussel Mytilus edulis forms extensive beds on waveprotected sedimentary shores, and the northerncentral coast of Chile, where the purple mussel Perumytilus purpuratus occurs predominantly on wave-exposed hard bottoms. In the Wadden Sea, several successful biological invasions (Baird et al. 2012, Buschbaum et al. 2012), weak post-settlement density dependence of dominant bivalves (Van der Meer et al. 2001), and strong seasonal variability in environmental conditions and settlement (Dittmann 1999) suggest that the composition of early colonisers may have significant effects on the pattern of colonisation of successional assemblages. On the other hand, settlement supply along the northern-central Chilean coast is comparatively moderate (Navarrete et al. 2005). Moreover, the strong top-down control and mechanical disturbances that usually characterise temperate wave-exposed rocky shores may limit the effects of settlement variations on successional patterns (Paine \& Levin 1981, Berlow 1997). Therefore, more canalised successional dynamics (sensu Berlow 1997) might be expected on the predominantly wave-exposed shores. Both systems were analysed separately as an initial attempt to find colonisation patterns in mussel assemblages developing under such different conditions.

At each study site, we tested the null hypothesis that irrespective of functional group (i.e. mobile or sessile species) and the time when substratum becomes available for colonisation, succession proceeds as a predictable sequence of changes in diversity and community structure resulting from the development of 'early' to 'late' assemblages. From this hypothesis, we derived the predictions that succession develops 
as a net increase in the number of taxa (e.g. Connell 1978) and that community structure progressively changes during succession from one structure to a different one. To test these predictions, we used an experimental design in which colonisation patterns that remained similar between habitat patches cleared at different times were considered as evidence for consistent sequences of change during succession.

\section{MATERIALS AND METHODS}

\section{Study sites}

The surveys on the succession of assemblages living in soft-bottom mussel beds of Mytilus edulis (maximum shell length $=75 \mathrm{~mm}$ ) were performed in a sheltered tidal bay at the northern tip of the island of Sylt in the northern Wadden Sea (German Bight, North Sea; $55^{\circ} 02^{\prime} \mathrm{N}, 08^{\circ} 26^{\prime} \mathrm{E}$ ). The bay is protected from strong onshore westerly winds by dunes, and intertidal habitats are dominated by sandy sediments (for more details, see Reise et al. 1994). Epibenthic bivalve beds extend from mid intertidal to adjacent subtidal zones, where they form 3-dimensional hard structures on soft sediments.

The experiment on assemblages associated with hard-bottom beds of Perumytilus purpuratus (maximum shell length $=40 \mathrm{~mm}$ ) was conducted in a moderately wave-exposed bay on the northern-central coast of Chile (Bahía Totoralillo Centro; $30^{\circ} 03^{\prime} \mathrm{S}$, $\left.71^{\circ} 28^{\prime} \mathrm{W}\right)$. At Totoralillo Centro, beds of P. purpuratus occur in the intertidal zone on large emergent rocks (between 2 and 20 m diameter) surrounded by sand. Mussel aggregations at Totoralillo Centro are mussel bed islands along the coastline north of $32^{\circ} \mathrm{S}$, where recruitment of $P$. purpuratus and other invertebrates is comparatively low (Navarrete et al. 2005).

\section{Experimental design and setup}

The experiment on colonisation in soft-bottom mussel beds (Mytilus edulis, Germany) was conducted between April and October 2002, and the experiment in hard-bottom mussel beds (Perumytilus purpuratus, Chile) was conducted between December 2002 and June 2003. The German experiment spanned from early spring to early fall, and the Chilean experiment spanned from late spring to late fall.

Mesh bags filled with adult mussels were used as habitat units (Fig. S1 in the supplement, available at www.int-res.com/articles/suppl/m497p131_supp.pdf) in a design that separates the changes in diversity caused by successional age of mussel substrata from those caused by the moment at which mussel patches were offered to the colonisers (i.e. duration and timing of deployment, respectively; see also Underwood \& Chapman 2006). Mussel patches were set out for 1 to 6 mo, with 1-, 2-, 3-, 4-, 5-, or 6-mo-old treatments deployed at different starting times over the duration of the experiment $(n=3)$. At each site, a series of 15 mussel replicate bags were set out at the beginning of the experiment; 3 replicates were sampled each month, from the beginning until the end of the experiment (treatments denoted with black lines in Fig. 1). In addition, 3 new bags with mussels were set out each month and sampled after 1 mo of exposure (treatments T2 to T6 in Fig. 1). The design furthermore included 3 mussel bags that were set out each month to be sampled at the end of the experiment (T8, T10, T12, and T14 in Fig. 1). After 3 to 4 mo of deployment, the experimental mussel patches showed similar values of species richness as reference patches from adjacent areas, confirming that the experimental units harboured a representative species assemblage of the study areas (Fig. S2 in the supplement).

In the field, mussels for the experiment were collected using a corer with a diameter of $10.5 \mathrm{~cm}$ (corresponding to an area of $86 \mathrm{~cm}^{2}$ ). Sediment and biota, including mobile and sessile organisms, were carefully removed. The cleaned mussels and empty shells of dead mussels from each corer sample were then transferred into $15 \times 15 \mathrm{~cm}$ bags made of $0.9 \times 0.9 \mathrm{~cm}$ PVC netting. In the German experiment, bags were fixed to the sediment with two $50 \times 0.6 \mathrm{~cm}$ iron rods, and in the Chilean experiment, bags were fastened to the underlying rock substratum with hook screws (6 cm length, $0.5 \mathrm{~cm}$ diameter) and plastic plugs. At both study sites, mussel bags were deployed within large natural mussel patches (Fig. S1 in the supplement). Our mussel bags provided the secondary settlement substratum typical for natural mussel populations and mimicked mid-late successional stages dominated by relatively large and dense mussels, similar to conditions in Koivisto et al. (2011) and Largaespada et al. (2012).

At each sampling date, experimental mussel patches were carefully removed from the mussel bed and enclosed in plastic bags or placed in plastic jars. Special care was taken in collecting all associated mobile and sessile organisms. Samples were kept in buffered formalin $(7 \%)$ until they were processed in the laboratory. Mussel patches were washed over a $500 \mu \mathrm{m}$ sieve, and all mobile organisms as well as sessile algae and invertebrates attached to the mus- 


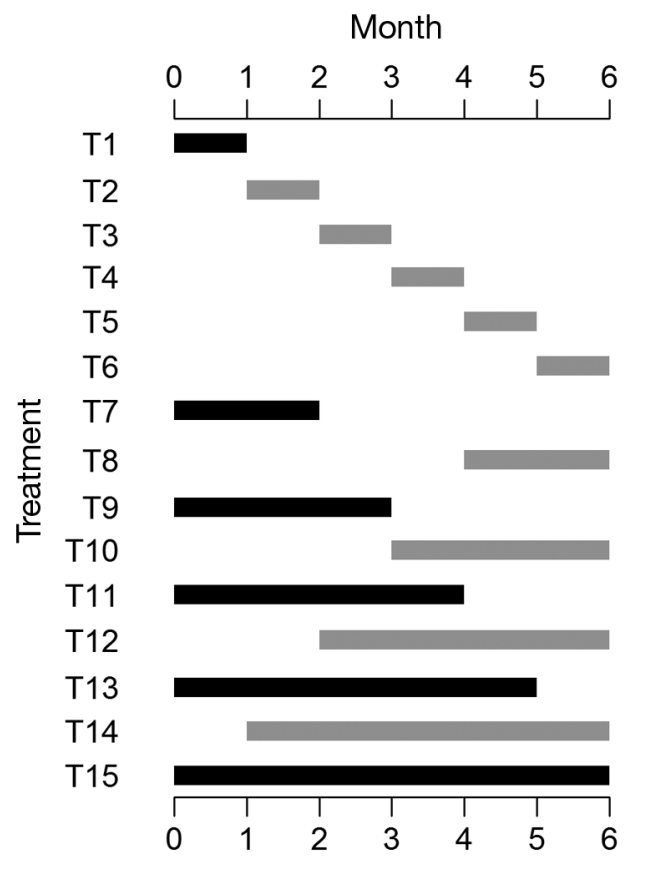

Fig. 1. Design of the experiment conducted to separate the effects of successional age (i.e. duration of deployment) from timing of deployment of settlement substrata. Treatments T1 to T6 were deployed starting in Months 0 to 6 for $1 \mathrm{mo}$, T7 and T8 were deployed in Months 0 and 4 for 2 mo, T9 and T10 were deployed in Months 0 and 3 for 3 mo, T11 and T12 were deployed in Months 0 and 2 for 4 mo, T13 and T14 were deployed in Months 0 and 1 for 5 mo, and T15 was deployed in Month 0 for 6 mo. All treatments consisted of $225 \mathrm{~cm}^{2}$ mussel patches with 3 replicates. Experiments were conducted in Mytilus edulis and Perumytilus purpuratus mussel beds in Germany and Chile, respectively. Black bars represent treatments deployed in Month 0 ; grey bars represent treatments deployed between Months 1 and 5

sel shells were identified to the lowest possible taxonomic level using a dissecting microscope and a binocular microscope. Mobile organisms and barnacles were quantified as number of individuals per mussel patch. Following Dean \& Connell (1987), encrusting algae and colonial invertebrates attached to mussel shells were quantified as number of patches per mussel patch, while erect algae were counted as number of plants per mussel patch. Species richness was then estimated as the number of taxa per mussel patch.

\section{Data analyses}

Species composition in terms of age of succession

The prediction that species richness increases with age of succession (i.e. duration of deployment) was tested separately for each study site and functional group (mobile and sessile) with a 1-way ANOVA with treatment as a fixed factor and followed by a linear contrast of species richness over age; a significant and positive relationship of species richness with successional age would support the prediction.

\section{Species composition in terms of timing of deployment}

For each study site, we used 2 sets of planned contrasts to test whether the variation of species richness with successional age depended on timing of deployment. First, we compared each of the 1-mo-old treatments (T1 to T6 in Fig. 1) with the mean value of all 1-mo-old treatments. To assure the independence among comparisons, i.e. to keep the number of contrasts below the number of groups to be compared, the 3 replicate mussel patches from one of the 1-moold treatments were removed. We removed T6 because it was the only treatment deployed during Month 5. Therefore, T6 was of limited value to predict timing effects on older assemblages. Any significant difference between species assemblages of the respective treatments and the mean of all 1-mo-old treatments would indicate an anomaly in settlement in terms of species richness and species abundances. Second, we used planned comparisons between older mussel patches of the same age but with different timings of deployment (i.e. T7 vs. T8, T9 vs. T10, T11 vs. T12, and T13 vs. T14 in Fig. 1). Here, significant differences in the comparisons indicate timing effects on species richness and species abundances, indicating that successional patterns vary across timings.

Species richness of sessile and mobile organisms was analysed separately. In addition, we were interested in determining the temporal patterns of dominant species from sessile and mobile assemblages. These taxa included sessile filter feeders (barnacles) and mobile grazers (amphipods) at each study site.

\section{Community structure analysis}

Patterns in community structure were graphically explored using canonical analysis of principal coordinates (CAP, Anderson \& Willis 2003). CAP is a constrained multivariate method that uses an a priori hypothesis to produce an ordination plot, allowing the detection of patterns that could be masked by overall dispersion in unconstrained methods such as multidimensional scaling. CAP plots were based on a 
matrix of factors (duration and timing of deployment) fitted to a matrix of Bray-Curtis dissimilarities calculated from raw abundance data. We used 2 subsets of treatments to test whether community structure progressively changes over succession from one structure to another: one subset included those treatments started in Month 0 and sampled at increasing ages (i.e. T1, T7, T9, T11, T13, and T15 in Fig. 1; referred to hereafter as the START series), and a second subset included those treatments initiated with different timings (from Month 0 to 5) and sampled together at the end of the experiment in Month 6 (i.e. T6, T8, T10, T12, T14, and T15 in Fig. 1; referred to hereafter as the END series). The rationale of this analysis was that if both series showed similar multivariate patterns, then it could be assumed that those patterns were independent of the timing of deployment. Both series were distinguished in ordination plots computed for each site and mobility group. For each series, the significance for sequential change in community structure was tested using a Mantel test, in which the cross-product $r_{\mathrm{M}}$ statistic was calculated between the rank-transformed matrices of BrayCurtis dissimilarities and those of the Euclidean distances between sampling dates (Legendre \& Legendre 2012). We used 9999 permutations of dissimilarity data to assess the significance of the $r_{\mathrm{M}}$ correlation coefficient. A significant correlation indicates that community structure followed a sequential pattern of change over time. We conducted separate analyses for the START and END series for each study site and mobility group.

Homogeneity of variance was graphically explored using scatterplots of residuals vs. fits and normal Q-Q plots to decide on appropriate transformations. When needed, data were square root transformed. We conducted all analyses in R version 2.13.1 (R Development Core Team 2012).

\section{RESULTS}

\section{Species occurrence}

At the Mytilus edulis study site (Germany), 52 taxa, belonging to 14 higher taxonomic units, were found (Table S1 in the supplement, available at www. int-res.com/articles/suppl/m497p131_supp.pdf); 25 sessile and 27 mobile species were recorded during this experiment. Sessile and mobile organisms were registered with $504.3 \pm 60.9$ and $114.9 \pm 9.7$ ind. or colonies per mussel patch (mean \pm standard error of the mean), respectively. Crustacea, algae, and
Annelida were the more abundant higher taxonomic units, representing $77.6,8.2$, and $5.2 \%$ of the community, respectively. The most abundant taxa were unidentified juvenile balanids $(262.8 \pm 60.6$ ind. per mussel patch) and the barnacles Balanus crenatus (113.0 \pm 29.3 ind. per mussel patch) and Austrominius modestus (37.2 \pm 8.2 ind. per mussel patch).

In the experiment conducted in Perumytilus purpuratus beds (Chile), 92 taxa were identified, which also represented 14 higher taxonomic units (Table S2 in the supplement). We registered 69 mobile and 23 sessile species. On average, $151.1 \pm 10.2$ sessile and $99.7 \pm 8.0$ mobile organisms or colonies occurred per mussel patch. The dominant higher taxonomic units were Bivalvia $(42.9 \%)$, Crustacea $(28.6 \%)$, Gastropoda $(8.2 \%)$, and Annelida (6.6\%). The numerically dominant taxa were the juveniles of $P$. purpuratus with $104.6 \pm 5.6$ ind. per mussel patch, the barnacle Jehlius cirratus with $27.1 \pm 6.5$ ind. per mussel patch, and the amphipod Apohyale grandicornis with $14.1 \pm 1.8$ ind. per mussel patch (Table S2 in the supplement).

\section{Temporal dynamics of sessile species}

Overall, temporal dynamics of sessile species richness varied across study sites, providing limited support for the hypothesis that species richness increases linearly during colonisation. In Germany, the number of sessile species increased significantly as successional age increased (Fig. 2A, Table 1). However, timing of deployment was important, as can be seen by the differences between settled species in 1mo-old mussel patches (T1 to T6). Accordingly, significant settlement anomalies (i.e. significant differences between a given 1-mo-old treatment and the average 1-mo-old mussel patch) were found during Months 2 and 3 (i.e. T3 and T4 in Table 1). Only the mussel patches set out at the onset of the experiment showed a net accumulation of species over time (black bars in Fig. 2A). All mussel patches set out later did not reach the species richness of the earliest mussels. Planned comparisons for 3-, 4-, and 5-moold assemblages supported these observations, as species richness in mussel patches deployed during Month 0 was significantly higher than that in mussel patches deployed during subsequent months (Table 1). The comparison between mussel patches deployed for 2 mo was non-significant (Table 1).

In Chile, the richness of sessile species increased with successional age, and settlement seemed to be more continuous than in Germany (Fig. 2B). Accord- 

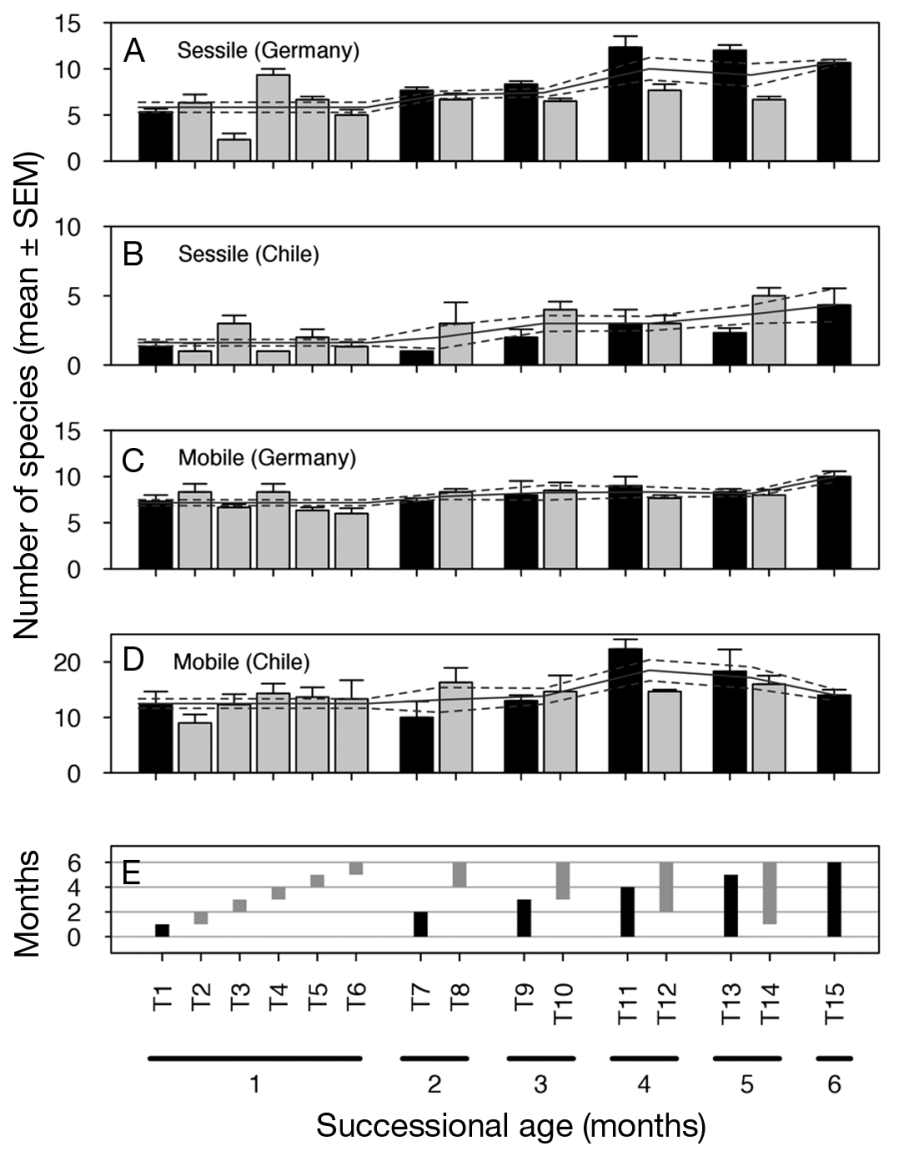

Fig. 2. Mean \pm SEM number of $(A, B)$ sessile and $(C, D)$ mobile species per treatment (T) in Germany and Chile. In (A) to (D), solid and dashed lines represent the mean and SEM values, respectively, of each level of successional age. (E) Timing of deployment and sampling of each treatment; the length of each bar indicates the successional age of each treatment. Black bars correspond to treatments deployed in Month 0 ingly, the planned linear contrast was significant, and none of the 1-mo-old comparisons showed significant differences (Table 1). The timing of deployment did not seem to affect the development of succession in terms of sessile species richness, as planned comparisons between mussel patches exposed for the same amount of time to colonisation but deployed in different months showed almost no significant differences, with the 5 -mo-old assemblages being the only exception (Table 1).

The average numbers of sessile species observed in 1-mo-old assemblages were 5.8 and 1.6 species, representing 55 and $37 \%$ of the maximum number of sessile species in Germany and Chile, respectively.

\section{Temporal dynamics of mobile species}

Richness of mobile species followed similar patterns at both sites, and timing of deployment had limited effects on colonisation patterns. In Germany, mobile species richness showed a slight, but still significant, increase with successional age (Fig. 2C, Table 1). We detected only one settlement anomaly (T4, Table 1). Timing of deployment had no effect on the succession of mobile species in Germany, as none of the contrasts between treatments deployed for the same number of months but at different times was significant (Table 1). Richness of Chilean mobile species increased significantly with duration of deployment across different timings (Fig. 2D, Table 1);

Table 1. ANOVA of the effects of successional age (i.e. duration of deployment) and timing of deployment on species richness of sessile and mobile organisms occurring in replicate experiments conducted in Germany and Chile. Treatments in each planned comparison are coded as in Fig. 1. Significant p-values at alpha $=0.05$ are in bold

\begin{tabular}{|c|c|c|c|c|c|c|c|c|c|}
\hline \multirow{3}{*}{$\begin{array}{l}\text { Source } \\
\text { of variation }\end{array}$} & \multirow[t]{3}{*}{ df } & \multicolumn{4}{|c|}{$\longrightarrow$ No. of sessile species } & \multicolumn{4}{|c|}{ No. of mobile species } \\
\hline & & \multicolumn{2}{|c|}{ — Germany —— } & \multicolumn{2}{|c|}{$\longrightarrow$ Chile -} & \multicolumn{2}{|c|}{ — Germany —— } & \multicolumn{2}{|c|}{ Chile } \\
\hline & & MS & $\mathrm{p}$ & MS & $\mathrm{p}$ & MS & $\mathrm{p}$ & MS & $\mathrm{p}$ \\
\hline Treatment $(\mathrm{T})$ & 14 & 21.4 & $<0.001$ & 4.90 & 0.003 & 3.22 & 0.046 & 31.2 & 0.047 \\
\hline $\mathrm{T}_{\text {Linear (T1-T15) }}$ & 1 & 127.0 & $<0.001$ & 35.92 & $<0.001$ & 20.14 & 0.001 & 126.7 & 0.007 \\
\hline $\mathrm{T}_{1 \text {-mo-old (T1 vs. mean 1-mo-old) }}$ & 1 & 0.9 & 0.369 & 0.28 & 0.669 & 0.10 & 0.801 & 0.1 & 0.936 \\
\hline (T2 vs. mean 1-mo-old) & 1 & 0.6 & 0.463 & 1.67 & 0.298 & 5.40 & 0.072 & 46.8 & 0.088 \\
\hline (T3 vs. mean 1-mo-old) & 1 & 49.0 & $<0.001$ & 5.44 & 0.065 & 0.11 & 0.791 & 4.7 & 0.581 \\
\hline (T4 vs. mean 1-mo-old) & 1 & 24.5 & $<0.001$ & 0.89 & 0.446 & 9.39 & 0.020 & 1.4 & 0.764 \\
\hline (T5 vs. mean 1-mo-old) & 1 & 4.2 & 0.059 & 0.67 & 0.509 & 0.17 & 0.745 & 0.2 & 0.917 \\
\hline $\mathrm{T}_{2 \text {-mo-old (T7 vs. T8) }}$ & 1 & 1.5 & 0.249 & 6.00 & 0.054 & 1.50 & 0.333 & 60.2 & 0.055 \\
\hline $\mathrm{T}_{3 \text {-mo-old (T9 vs. T10) }}$ & 1 & 5.0 & 0.039 & 6.00 & 0.054 & 0.38 & 0.626 & 4.2 & 0.603 \\
\hline $\mathrm{T}_{4 \text {-mo-old (T11 vs. T12) }}$ & 1 & 32.7 & $<0.001$ & $<0.01$ & 1.000 & 2.67 & 0.200 & 88.2 & 0.022 \\
\hline $\mathrm{T}_{5 \text {-mo-old (T13 vs. T14) }}$ & 1 & 42.7 & $<0.001$ & 10.67 & 0.012 & 0.17 & 0.745 & 8.2 & 0.468 \\
\hline Residuals & 30 & 1.1 & & 1.49 & & 1.55 & & 15.1 & \\
\hline
\end{tabular}


in addition, only the planned comparison between 4-mo-old assemblages was significant (Table 1). The average 1-mo-old assemblages of mobile species harboured 7.2 and 12.5 species, which represented 77 and $68 \%$ of the maximum number of mobile species in Germany and Chile, respectively.

\section{Temporal dynamics of dominant sessile and mobile species}

Timing of deployment seemed to have stronger effects on the abundance of dominant suspension feeders and grazers in Germany than in Chile. In Germany, a significant settlement anomaly of barnacles (Balanus crenatus, Austrominius modestus, Semibalanus balanoides, and unidentified juvenile barnacles) occurred during the first month of the experiment (Fig. 3A, T1 in Table 2). Planned contrasts within 2- and 3-mo-old assemblages showed that abundance of barnacles was significantly higher in treatments deployed in Month 0 (Table 2). No significant differences were observed between older assemblages. Therefore, abundances of barnacles in mussel patches that captured the settlement peak in Month 0 decreased during the months after the initial settlement and then stabilised. In addition, at the end of the experiment, the mussels that did not capture the initial settlement peak had similar barnacle abundances as the mussels that had captured the initial peak.
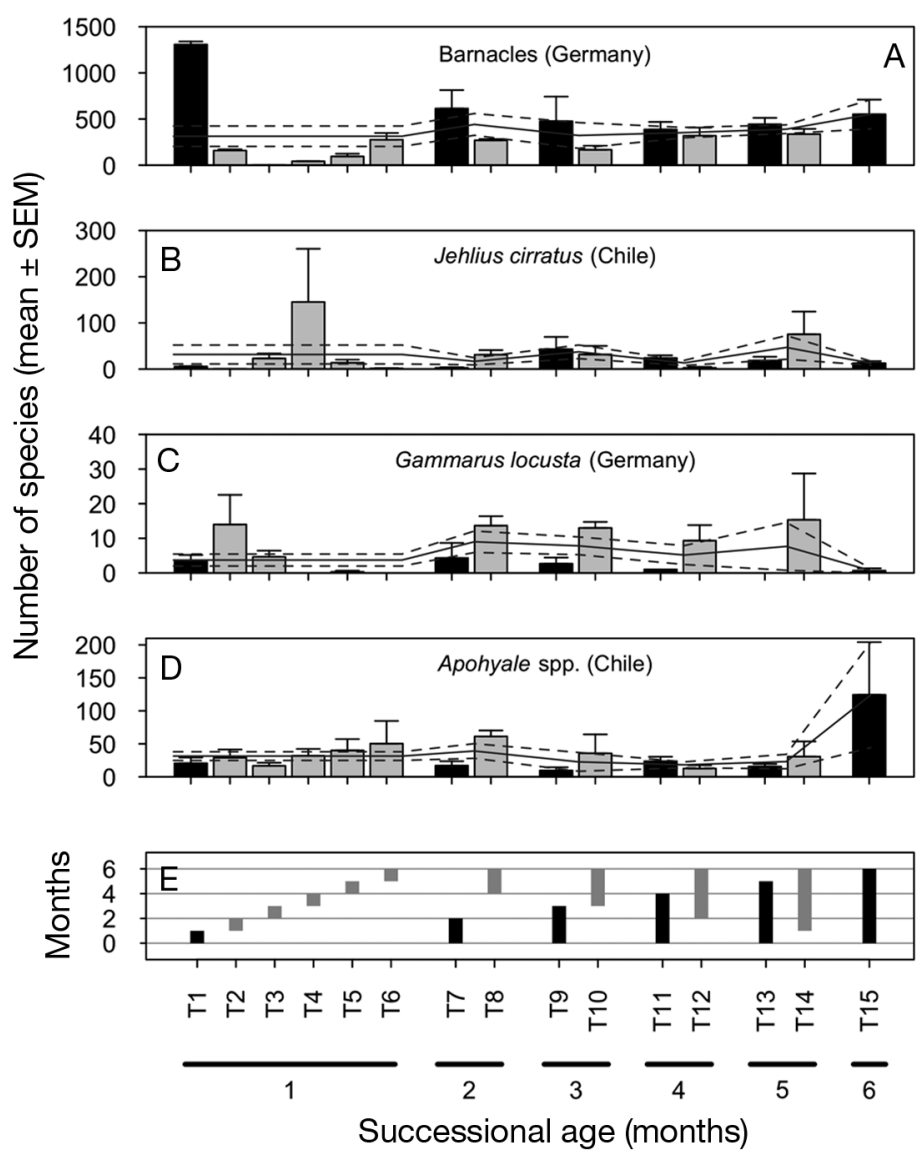

Fig. 3. Mean \pm SEM abundance of $(A, B)$ sessile and $(C, D)$ mobile dominant species per treatment $(\mathrm{T})$ in Germany and Chile. In $(\mathrm{A})$ to (D), solid and dashed lines represent the mean and SEM values, respectively, of each level of successional age. (E) Timing of deployment and sampling of each treatment; the length of each bar indicates the successional age of each treatment. Black bars correspond to treatments deployed in Month 0

Table 2. ANOVA of the effects of successional age (i.e. duration of deployment) and timing of deployment on the abundance of dominant species occurring in replicate experiments in Germany and Chile. Data for Gammarus locusta were square root transformed. Treatments in each planned comparison are coded as in Fig. 1. Significant p-values at alpha $=0.05$ are in bold

\begin{tabular}{|c|c|c|c|c|c|c|c|c|c|}
\hline \multirow[t]{2}{*}{$\begin{array}{l}\text { Source } \\
\text { of variation }\end{array}$} & \multirow[t]{2}{*}{$\mathrm{df}$} & \multicolumn{2}{|c|}{$\begin{array}{l}\text { Barnacles } \\
\text { Germany }\end{array}$} & \multicolumn{2}{|c|}{$\begin{array}{c}\text { Jehlius cirratus } \\
\text { Chile }\end{array}$} & \multicolumn{2}{|c|}{$\begin{array}{c}\text { Gammarus locusta } \\
\text { Germany }\end{array}$} & \multicolumn{2}{|c|}{$\begin{array}{c}\text { Apohyale spp. } \\
\text { Chile }\end{array}$} \\
\hline & & MS & $\mathrm{p}$ & MS & $\mathrm{p}$ & MS & $\mathrm{p}$ & MS & $\mathrm{p}$ \\
\hline Treatment $(\mathrm{T})$ & 14 & 302570 & $<0.001$ & 4303 & 0.289 & 5.57 & 0.003 & 2465 & 0.289 \\
\hline $\mathrm{T}_{\text {Linear (T1-T15) }}$ & 1 & 81826 & 0.129 & 19 & 0.940 & 0.04 & 0.872 & 3334 & 0.202 \\
\hline $\mathrm{T}_{1 \text {-mo-old (T1 vs. mean 1-mo-old) }}$ & 1 & 3551365 & $<0.001$ & 2413 & 0.408 & 0.68 & 0.526 & 418 & 0.648 \\
\hline (T2 vs. mean 1-mo-old) & 1 & 7107 & 0.649 & 4969 & 0.238 & 18.83 & 0.002 & 79 & 0.842 \\
\hline (T3 vs. mean 1-mo-old) & 1 & 40737 & 0.280 & 2085 & 0.441 & 8.73 & 0.029 & 1308 & 0.420 \\
\hline (T4 vs. mean 1-mo-old) & 1 & 41089 & 0.278 & 37996 & 0.002 & 0.06 & 0.856 & 347 & 0.677 \\
\hline (T5 vs. mean 1-mo-old) & 1 & 49323 & 0.236 & 228 & 0.798 & 0.17 & 0.753 & 160 & 0.777 \\
\hline $\mathrm{T}_{2 \text {-mo-old (T7 vs. T8) }}$ & 1 & 177160 & 0.029 & 1204 & 0.558 & 9.08 & 0.026 & 2948 & 0.230 \\
\hline $\mathrm{T}_{3 \text {-mo-old (T9 vs. T10) }}$ & 1 & 143067 & 0.048 & 193 & 0.814 & 7.94 & 0.037 & 1014 & 0.478 \\
\hline $\mathrm{T}_{4 \text {-mo-old (T11 vs. T12) }}$ & 1 & 6734 & 0.658 & 683 & 0.658 & 5.26 & 0.085 & 182 & 0.763 \\
\hline $\mathrm{T}_{5 \text {-mo-old (T13 vs. T14) }}$ & 1 & 16960 & 0.483 & 4874 & 0.242 & 11.99 & 0.012 & 338 & 0.681 \\
\hline Residuals & 30 & 33656 & & 3425 & & 1.66 & & 1961 & \\
\hline
\end{tabular}


In Chile, the peak of barnacle (Jehlius cirratus) settlement occurred during Month 3 (Fig. 3B, T4 in Table 2). Planned contrasts showed no significant differences between treatments deployed for the same amount of time but in different months (Table 2). Therefore, it seems that this settlement peak had no effect on the abundance of barnacles during the development of succession.

Grazing amphipods in Germany (Gammarus locusta) showed positive and significant settlement anomalies during Months 1 and 2 (Fig. 3C, T2 and T3 in Table 2 [square-root transformed data]). Planned contrasts showed that amphipods were more abundant in all later deployments than in the Month 0 deployment, except for the 4-mo-old assemblages (T11 vs. T12 comparison in Table 2). In Chile, the analyses showed no significant differences in any of the comparisons for the abundance of grazing amphipods (Apohyale spp., Table 2).

\section{Sequential changes in community structure}

CAP showed different patterns of community structure between study sites (Fig. 4). In Germany, both ses- sile and mobile species displayed significant sequential changes in community structure (Fig. 4A, $\mathrm{C}_{i}$ Table 3). However, the ordinations showed relatively large multivariate dissimilarities (i.e. distances) between mussel patches of the same age but with different timings of deployment (i.e. START vs. END); these dissimilarities were larger for sessile species than for mobile species (Fig. 4A,C). In Chile, on the other hand, only the START series of mobile species showed a significant multivariate sequential pattern (Fig. 4B, $\mathrm{D}_{\text {; }}$ Table 3).

\section{DISCUSSION}

Our results showed that colonisation dynamics differed between timings of deployment and between sessile and mobile species, providing limited support for the model of a linear and sequential development of succession. For sessile organisms, species richness increased over time at both study sites, but the magnitude of this increase varied across different timings of deployment at the sedimentary site (i.e. Germany). For mobile organisms, most species colonised the mussel patches during the first month of deployment. After that settlement peak, there was a consistent,

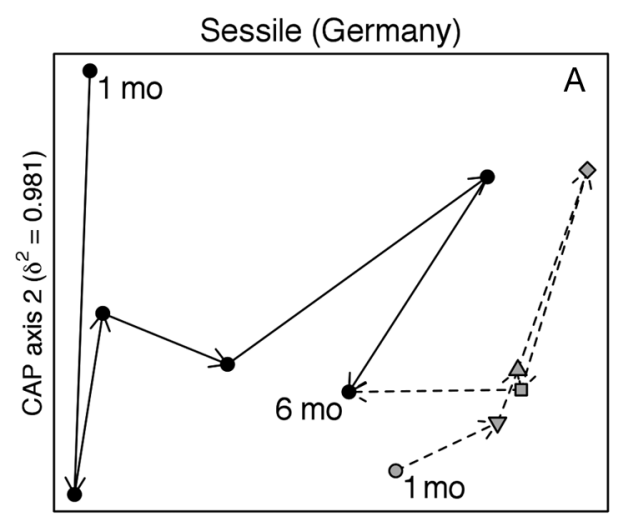

CAP axis $1\left(\delta^{2}=0.989\right)$

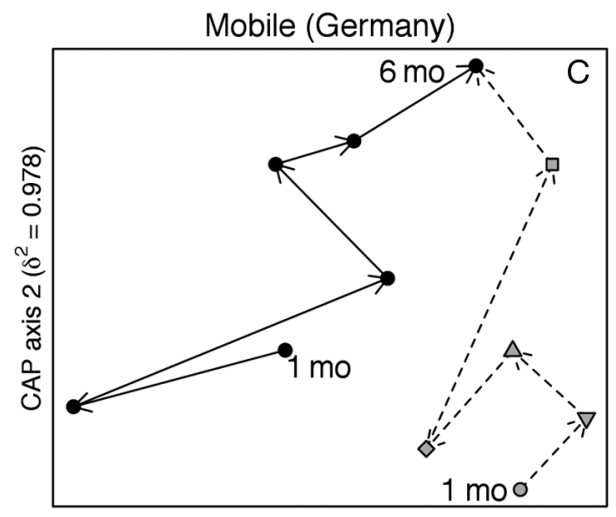

CAP axis $1\left(\delta^{2}=0.990\right)$
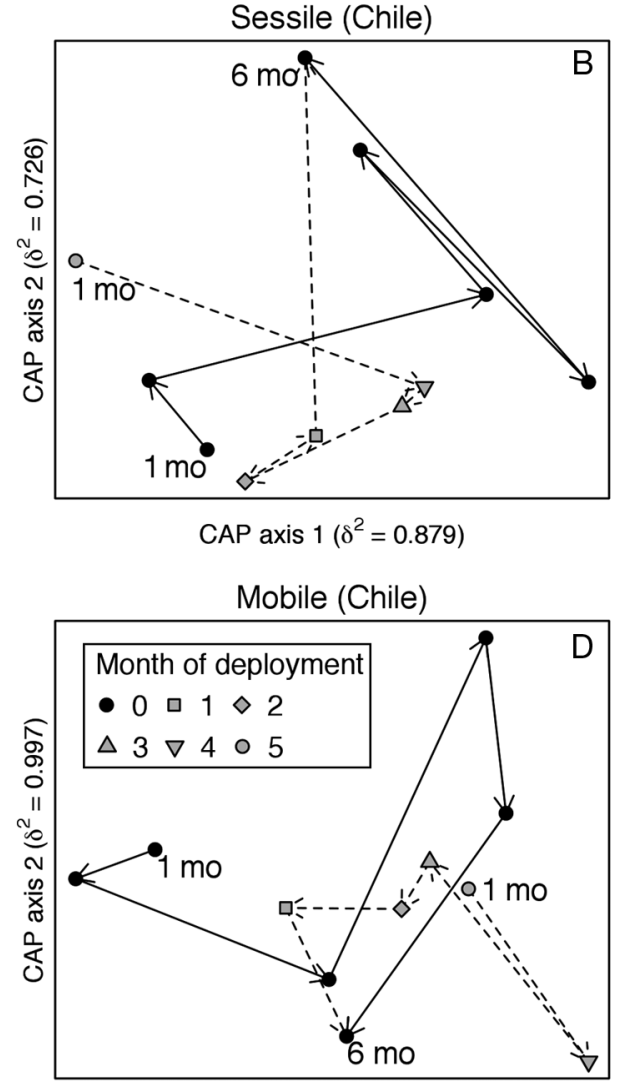

CAP axis $1\left(\delta^{2}=0.999\right)$
Fig. 4. Canonical coordinate analysis (CAP) ordinations of assemblages of $(A, B)$ sessile and $(\mathrm{C}, \mathrm{D})$ mobile species in Germany and Chile. Each symbol corresponds to the centroid $(\mathrm{n}=3)$ of a given treatment. Black symbols denote treatments deployed in Month 0 and sampled at increasing durations of time (START series). Grey symbols correspond to treatments initiated with different timings (from Month 0 to 5) and sampled together at the end of the experiment in Month 6 (END series). $1 \mathrm{mo}$ and $6 \mathrm{mo}$ correspond to 1- and 6-monthold assemblages, respectively 
Table 3. Sequential changes in community structure. Results of Mantel tests between ranked Bray-Curtis community dissimilarities and Euclidean distances between sampling dates. We used 9999 permutations of dissimilarity data to assess the significance of the $r_{\mathrm{M}}$ correlation coefficient. START series are treatments initiated with same timing of deployment (Month 0) and sampled at increasing ages (1 mo intervals); END series are treatments initiated with different timings (from Month 0 to 5) and sampled together at the end of the experiment in Month 6

\begin{tabular}{|c|c|c|c|c|c|}
\hline \multirow{3}{*}{$\begin{array}{l}\text { Study } \\
\text { site }\end{array}$} & \multirow[t]{3}{*}{ Mobility } & \multicolumn{4}{|c|}{$\longrightarrow$ Series } \\
\hline & & \multicolumn{2}{|c|}{- START -} & \multicolumn{2}{|c|}{$\longrightarrow$ END } \\
\hline & & $r_{\mathrm{M}}$ & $\mathrm{p}$ & $\mathrm{r}_{\mathrm{M}}$ & $\mathrm{p}$ \\
\hline \multirow{2}{*}{ Germany } & Sessile & 0.5332 & 0.0001 & 0.297 & 0.0017 \\
\hline & Mobile & 0.3453 & 0.0009 & 0.453 & 0.0001 \\
\hline \multirow[t]{2}{*}{ Chile } & Sessile & 0.1198 & 0.0910 & 0.027 & 0.3662 \\
\hline & Mobile & 0.2320 & 0.0087 & -0.014 & 0.5368 \\
\hline
\end{tabular}

albeit minor, temporal increase in mobile species richness at both study sites. Accordingly, coloniser mobility seems to play a relevant role in the successional patterns of assemblages associated with complex biogenic substrata.

\section{Colonisation patterns of mobile species}

The taxonomic richness of mobile species showed consistent patterns across the 2 study sites. Species richness measured after 1 mo of colonisation at both sites was higher for mobile species than for sessile species, suggesting that mobile species can rapidly invade recently disturbed patches of habitats. Averaged across different timings, a high percentage $(>65 \%)$ of the maximal number of mobile species was already present after 1 mo. This means that most mobile species arrived within the first month after exposure to colonisation. Larvae, juveniles, and adults of mobile taxa can colonise recently disturbed habitats, leading to comparatively rapid colonisation rates and homogenisation of the landscape (Soininen 2010). In sedimentary environments, the abundance of mobile species is positively related to community stability, because mobile organisms quickly reoccupy recently disturbed habitat patches (Dittmann 1999, Pacheco et al. 2012). This may explain the minor temporal increase in species richness of mobile species observed at both study sites. Succession of these assemblages probably developed as a net addition of taxa over time, but the number of arrivals was only slightly larger than losses of previously arrived taxa because most potential members should have already arrived.
At both study sites, dominant amphipods showed no increase in abundance during succession. This suggests that within a month, the dominant amphipods reached densities similar to those measured in older assemblages, as shown in previous manipulative studies. For instance, experimentally defaunated patch habitats such as algal and seagrass mats showed daily turnover rates of amphipods between 30 and 100\% (Edgar 1992, Taylor 1998, Poore 2005). These results indicate that successional assemblages of mobile species can reach pre-disturbance densities within a day. In our study, it is therefore likely that local dispersal abilities of mobile species led to a rapid convergence between assemblages when the same kind of substrata were deployed at different times, which probably occurred within the first month of substratum availability. Depending on the degree to which mobile species are resident (almost always present) or transient (low frequency of occurrence over time), assemblages dominated by mobile species can show a comparatively high resilience to disturbances (Pimm 1984, Costello \& Myers 1996).

Given the high colonisation rates of mobile species observed in our study, it is relevant to ask what mechanisms are involved in the re-colonisation of complex biogenic habitats. Most of the experimental mussel bags were deployed in direct contact with the natural bed. Therefore, it is likely that mobile organisms actively crawled from 'source' patch habitats to the experimental mussel bags. Dispersal by crawling can have a high adaptive value, as it may reduce the risk of detection by visual predators such as demersal fish (Taylor 1998). Nevertheless, other mechanisms of local dispersal cannot be ruled out. For example, dispersal by swimming can also lead to high colonisation rates, irrespective of the distance between patches of habitats (Poore 2005). Mobile species, such as the polychaete Nereis diversicolor, can also shift from swimming (juveniles) to crawling (adults) behaviours during their life history (Aberson et al. 2011). Moreover, drifting algae can act as mobile corridors between habitat patches, allowing for passive dispersal at local and regional scales (Brooks \& Bell 2001, Thiel 2002). Therefore, multiple mechanisms likely mediate the colonisation of complex and patchy habitats by mobile species.

\section{Context-dependent dynamics of sessile species}

The temporal patterns of sessile species richness varied between study sites. At the sedimentary 
coast of Germany, sessile species richness increased over time only in mussel patches deployed during the main settlement period of barnacles (in April). High abundances of early sessile colonisers can facilitate the establishment of additional species when the former increase habitat complexity and, thus, also increase shelter and anchoring substrata (Maggi et al. 2011). In addition, higher diversity of sessile species further increases the variety of physical structures in the habitat, which can improve the niche complementarity among colonisers (e.g. Cardinale et al. 2002). In Germany, therefore, the composition of the species that happened to colonise first may have influenced the process of community assembly.

These results point to the relevance of including the initial variation in settler abundances in the analysis of succession. Successional assemblages can track the variation in composition and abundance of early settlers when extrinsic factors such as environmental conditions, settler supply, and disturbances override the effects of local biotic interactions (Berlow 1997). In these cases of externally driven succession (sensu Berlow 1997), models assuming that early and late colonisers coexist over time may offer a high predictive power (e.g. Connell \& Slatyer's [1977] tolerance model).

On the other hand, early composition of sessile species at the rocky intertidal site of Chile showed little variation, leading to non-significant effects of timing of initiation on older assemblages. Physical and ecological characteristics of rocky shores might explain the lack of timing effects in Chile. Seasonality in oceanographic conditions and recruitment seems to be relatively moderate along the northern-central coast of Chile (Navarrete et al. 2005), which could have resulted in non-significant timing effects on the diversity of early settlers. In addition, rocky shores usually show comparatively high levels of wave exposure (Raffaelli \& Hawkins 1996), which can reduce recruitment by inducing mortality or emigration of recently settled colonisers (Porri et al. 2008). Alongshore gradients of wave exposure have been shown to correlate with species abundances and diversity, in agreement with environmental stress models of community assembly (Menge \& Sutherland 1987, Scrosati et al. 2011). Furthermore, rocky intertidal shores in north-central Chile harbour diverse assemblages of mobile consumers that can reduce the abundance of early sessile colonists (Aguilera 2011). Accordingly, abiotic and biotic sources of disturbances at the rocky shore site could have triggered a high post-settlement mortality of sessile colonisers, dampening the potential initial variation in settler supply.

\section{Secondary succession in biogenic substrata}

Several studies have shown deterministic and canalised (sensu Berlow 1997) patterns of succession. For example, Underwood \& Chapman (2006) reported that different assemblages of early colonisers on scour pads converge into similar communities during succession. Experiments in epibenthic soft- and hardbottom subtidal assemblages suggest that regardless of the starting conditions, dominance by competitively superior species leads to similar community structures in advanced successive stages (Cifuentes et al. 2010, Antoniadou et al. 2011, Pacheco et al. 2011). Solitary ascidians (Yakovis et al. 2008) and intertidal mussels (Paine 1980, Tokeshi \& Romero 1995) monopolise the primary substratum regardless of whatever community was developing initially. Finally, intertidal grazers can restrict the abundance of opportunistic algae and favour the establishment of slow-growing corticated algae, which dominate the climactic structure of the community on the coasts of central Chile (Nielsen \& Navarrete 2004, Aguilera \& Navarrete 2007).

The apparent discrepancy between the examples outlined above and our results can be explained by the presumed weakness of competitive hierarchies, which are pivotal in models of canalised succession (e.g. Connell \& Slatyer 1977, Huston \& Smith 1987, Farrell 1989, Platt \& Connell 2003), within complex biogenic habitats (Bruno et al. 2003, Bulleri et al. 2008). Biogenic substrata such as turf-forming algae and mussel beds provide enhanced habitat complexity for smaller species, reducing the strength of competition for anchoring surfaces (Bruno et al. 2003) and the occurrence of antagonistic interactions between territorial mobile organisms (Dean \& Connell 1987), which can increase the invasibility of the assemblage (Bulleri et al. 2008). For example, transient mobile species can contribute a high proportion of the associated species in structurally complex habitats, indicating that a significant percentage of species richness in these habitats depends on the movement of individuals from nearby areas (Costello \& Myers 1996). Competition is likely to have stronger effects on sessile species than on mobile species, as the latter can avoid competitive interactions by emigrating into nearby habitat patches (e.g. Wieters et al. 2009). Accordingly, the strong focus on sessile colonisers in previous successional studies might have resulted in partly biased results. 


\section{CONCLUSIONS}

In summary, our separate analysis of sessile and mobile species provided the opportunity to use a more comprehensive approach to investigate succession of benthic marine communities than the usual focus on dominant sessile species in intertidal habitats. In comparison with the sedimentary study site in Germany, stressful conditions at the rocky site in Chile may have prevented significant effects of timing of deployment on colonisation dynamics. Despite large differences in biotic and abiotic characteristics, the mobile assemblage showed a high resilience at both study sites, as most mobile species appeared in the mussel habitats during the first month of colonisation. Our results suggest that dispersal ability at the local scale (mobility) may play an important role in determining how highly diverse assemblages respond to natural and anthropogenic disturbances.

Acknowledgements. We thank S. Boltaña, I. Hinojosa, A. Hinz, E. Rothäusler, P. Ugalde, and N. Vásquez for their support during field and laboratory work. L. B. Eastman polished the language of an early version of the manuscript, and 4 anonymous reviewers provided several helpful suggestions. This research was financially supported by grants 1010356 and N 2001-182 given to M.T. by the Fondo Nacional de Desarrollo Científico y Tecnológico de Chile (FONDECYT) and the Comisión Nacional de Investigación Científica y Tecnológica-Departamento de Relaciones Internacionales (CONICYT-DRI), respectively, in addition to grant CHL 01/021 given to C.B. by the International Bureau (IB) of the German Federal Ministry of Education and Research (BMBF). While writing, N.V. was supported by grant AUS0805 (Fortalecimiento de las Ciencias Ecológicas y Evolutivas en la Universidad Austral de Chile) by the Programa de Mejoramiento de la Calidad y la Equidad de la Educación Superior (MECESUP).

\section{LITERATURE CITED}

Aberson MJR, Bolam SG, Hughes RG (2011) The dispersal and colonisation behaviour of the marine polychaete Nereis diversicolor (O. F. Müller) in south-east England. Hydrobiologia 672:3-14

Aguilera MA (2011) The functional roles of herbivores in the rocky intertidal systems in Chile: a review of food preferences and consumptive effects. Rev Chil Hist Nat 84: 241-261

> Aguilera MA, Navarrete SA (2007) Effects of Chiton granosus (Frembly, 1827) and other molluscan grazers on algal succession in wave exposed mid-intertidal rocky shores of central Chile. J Exp Mar Biol Ecol 349:84-98

> Anderson MJ, Willis TJ (2003) Canonical analysis of principal coordinates: a useful method of constrained ordination for ecology. Ecology 84:511-525

> Antoniadou C, Voultsiadou E, Chintiroglou C (2011) Seasonal patterns of colonization and early succession on sublittoral rocky cliffs. J Exp Mar Biol Ecol 403:21-30
Baird D, Asmus H, Asmus R (2012) Effect of invasive species on the structure and function of the Sylt-Romo Bight ecosystem, northern Wadden Sea, over three time periods. Mar Ecol Prog Ser 462:143-161

> Benedetti-Cecchi L (2000a) Priority effects, taxonomic resolution, and the prediction of variable patterns of colonisation of algae in littoral rock pools. Oecologia 123:265-274

> Benedetti-Cecchi L (2000b) Variance in ecological consumer-resource interactions. Nature 407:370-374

$>$ Berlow EL (1997) From canalization to contingency: historical effects in a successional rocky intertidal community. Ecol Monogr 67:435-460

Bishop MJ, Byers JE, Marcek BJ, Gribben PE (2012) Density-dependent facilitation cascades determine epifaunal community structure in temperate Australian mangroves. Ecology 93:1388-1401

Brooks RA, Bell SS (2001) Mobile corridors in marine landscapes: enhancement of faunal exchange at seagrass/ sand ecotones. J Exp Mar Biol Ecol 264:67-84

> Bruno JF, Stachowicz JJ, Bertness D (2003) Inclusion of facilitation into ecological theory. Trends Ecol Evol 18: 119-125

Bulleri F, Bruno JF, Benedetti-Cecchi L (2008) Beyond competition: incorporating positive interactions between species to predict ecosystem invasibility. PLoS Biol 6:e162

Buschbaum C, Lackschewitz D, Reise K (2012) Nonnative macrobenthos in the Wadden Sea ecosystem. Ocean Coast Manage 68:89-101

Buss LW (1979) Bryozoan overgrowth interactions - the interdependence of competition for space and food. Nature 281:475-477

> Cardinale BJ, Palmer MA, Collins SL (2002) Species diversity enhances ecosystem functioning through interspecific facilitation. Nature 415:426-429

Cifuentes M, Kamlah C, Thiel M, Lenz M, Wahl M (2007) Effects of temporal variability of disturbance on the succession in marine fouling communities in northerncentral Chile. J Exp Mar Biol Ecol 352:280-294

Cifuentes M, Krueger I, Dumont CP, Lenz M, Thiel M (2010) Does primary colonization or community structure determine the succession of fouling communities? J Exp Mar Biol Ecol 395:10-20

> Connell JH (1978) Diversity in tropical rain forests and coral reefs. Science 199:1302-1310

> Connell JH, Slatyer RO (1977) Mechanisms of succession in natural communities and their role in community stability and organization. Am Nat 111:1119-1144

> Connolly SR, Muko S (2003) Space preemption, sizedependent competition, and the coexistence of clonal growth forms. Ecology 84:2979-2988

> Costello MJ, Myers AA (1996) Turnover of transient species as a contributor to the richness of a stable amphipod (Crustacea) fauna in a sea inlet. J Exp Mar Biol Ecol 202: $49-62$

> Dean TA, Connell JH (1987) Marine invertebrates in an algal succession. I. Variations in abundance and diversity with succession. J Exp Mar Biol Ecol 109:195-215

Dittmann S (ed) (1999) The Wadden Sea ecosystem: stability properties and mechanisms. Springer-Verlag, Berlin

Edgar GJ (1992) Patterns of colonization of mobile epifauna in a western Australian seagrass bed. J Exp Mar Biol Ecol 157:225-246

> Farrell TM (1989) Succession in a rocky intertidal community: the importance of disturbance size and position within a disturbed patch. J Exp Mar Biol Ecol 128:57-73 
Huston M, Smith S (1987) Plant succession: life history and competition. Am Nat 130:168-198

> Jones CG, Lawton JH, Shachak M (1994) Organisms as ecosystem engineers. Oikos 69:373-386

> Koivisto M, Westerbom M (2012) Invertebrate communities associated with blue mussel beds in a patchy environment: a landscape ecology approach. Mar Ecol Prog Ser 471:101-110

Koivisto M, Westerbom M, Riihimaki A (2011) Successiondriven facilitation of macrofaunal communities in sublittoral blue mussel habitats. Mar Biol 158:945-954

> Largaespada C, Guichard F, Archambault P (2012) Metaecosystem engineering: nutrient fluxes reveal intraspecific and interspecific feedbacks in fragmented mussel beds. Ecology 93:324-333

Legendre P, Legendre L (2012) Numerical ecology. Elsevier, Amsterdam

> Lohse DP (1993) The importance of secondary substratum in a rocky intertidal community. J Exp Mar Biol Ecol 166: $1-17$

Lotze HK, Lenihan HS, Bourque BJ, Bradbury RH, and others (2006) Depletion, degradation, and recovery potential of estuaries and coastal seas. Science 312:1806-1809

- Maggi E, Bertocci I, Vaselli S, Benedetti-Cecchi L (2011) Connell and Slatyer's models of succession in the biodiversity era. Ecology 92:1399-1406

Menge BA (1991) Generalizing from experiments: Is predation strong or weak in the New England rocky intertidal? Oecologia 88:1-8

> Menge BA, Sutherland JP (1987) Community regulation: variation in disturbance, competition, and predation in relation to environmental stress and recruitment. Am Nat 130:730-757

Navarrete SA, Wieters EA, Broitman BR, Castilla JC (2005) Scales of benthic-pelagic coupling and the intensity of species interactions: from recruitment limitation to top-down control. Proc Natl Acad Sci USA 102: 18046-18051

Nielsen KJ, Navarrete SA (2004) Mesoscale regulation comes from the bottom-up: intertidal interactions between consumers and upwelling. Ecol Lett 7:31-41

Norderhaug KM, Christie H, Rinde E (2002) Colonisation of kelp imitations by epiphyte and holdfast fauna; a study of mobility patterns. Mar Biol 141:965-973

Norkko A, Rosenberg R, Thrush SF, Whitlatch RB (2006) Scale- and intensity-dependent disturbance determines the magnitude of opportunistic response. J Exp Mar Biol Ecol 330:195-207

Pacheco AS, Laudien J, Thiel M, Oliva M, Heilmayer O (2011) Succession and seasonal onset of colonization in subtidal hard-bottom communities off northern Chile. Mar Ecol 32:75-87

> Pacheco AS, Thiel M, Oliva ME, Riascos JM (2012) Effects of patch size and position above the substratum during early succession of subtidal soft-bottom communities. Helgol Mar Res 66:523-536

Paine RT (1980) Food webs: linkage, interaction strength and community infrastructure. J Anim Ecol 49:667-685

Paine R, Levin SA (1981) Intertidal landscapes: disturbance and the dynamics of pattern. Ecol Monogr 51:145-178

> Pimm SL (1984) The complexity and stability of ecosystems. Nature 307:321-326
Platt WJ, Connell JH (2003) Natural disturbances and directional replacement of species. Ecol Monogr 73:507-522

Poore AGB (2005) Scales of dispersal among hosts in a herbivorous marine amphipod. Austral Ecol 30:219-228

Porri F, McQuaid CD, Lawrie SM, Antrobus SJ (2008) Finescale spatial and temporal variation in settlement of the intertidal mussel Perna perna indicates differential hydrodynamic delivery of larvae to the shore. J Exp Mar Biol Ecol 367:213-218

> Prach K, Walker LR (2011) Four opportunities for studies of ecological succession. Trends Ecol Evol 26:119-123

R Development Core Team (2012) R: a language and environment for statistical computing. R Foundation for Statistical Computing, Vienna

Raffaelli D, Hawkins S (1996) Intertidal ecology. Chapman \& Hall, London

Reise K, Herre E, Sturm M (1994) Biomass and abundance of macrofauna in intertidal sediments of Königshafen in the northern Wadden Sea. Helgol Mar Res 48:201-215

> Scrosati RA, van Genne B, Heaven CS, Watt CA (2011) Species richness and diversity in different functional groups across environmental stress gradients: a model for marine rocky shores. Ecography 34:151-161

Silliman BR, Bertness MD, Altieri AH, Griffin JN, and others (2011) Whole-community facilitation regulates biodiversity on Patagonian rocky shores. PLoS ONE 6:e24502

Smith JR, Fong P, Ambrose RF (2006) Dramatic declines in mussel bed community diversity: Response to climate change? Ecology 87:1153-1161

Soininen J (2010) Species turnover along abiotic and biotic gradients: Patterns in space equal patterns in time? Bioscience 60:433-439

> Taylor RB (1998) Short-term dynamics of a seaweed epifaunal assemblage. J Exp Mar Biol Ecol 227:67-82

> Thiel M (2002) The zoogeography of algae-associated peracarids along the Pacific coast of Chile. J Biogeogr 29: 999-1008

> Thiel M, Ullrich N (2002) Hard rock versus soft bottom: the fauna associated with intertidal mussel beds on hard bottoms along the coast of Chile, and considerations on the functional role of mussel beds. Helgol Mar Res 56: 21-30

> Thiel M, Zander A, Valdivia N, Baeza JA, Rueffler C (2003) Host fidelity of a symbiotic porcellanid crab: the importance of host characteristics. J Zool (Lond) 261:353-362

Tokeshi M, Romero L (1995) Filling a gap: dynamics of space occupancy on a mussel-dominated subtropical rocky shore. Mar Ecol Prog Ser 119:167-176

Underwood AJ, Chapman MG (2006) Early development of subtidal macrofaunal assemblages: relationships to period and timing of colonization. J Exp Mar Biol Ecol 330:221-233

> Van der Meer J, Beukema JJ, Dekker R (2001) Long-term variability in secondary production of an intertidal bivalve population is primarily a matter of recruitment variability. J Anim Ecol 70:159-169

Wieters EA, Salles E, Januario SM, Navarrete SA (2009) Refuge utilization and preferences between competing intertidal crab species. J Exp Mar Biol Ecol 374:37-44

> Yakovis EL, Artemieva AV, Shunatova NN, Varfolomeeva MA (2008) Multiple foundation species shape benthic habitat islands. Oecologia 155:785-795

Submitted: January 21, 2013; Accepted: October 9, 2013

Proofs received from author(s): December 23, 2013
Editorial responsibility: Brian Helmuth, Nahant, Massachusetts, USA 